\title{
Polyhedron method for early short circuit detection
}

\author{
Du Feng, Chen Weigang \\ Corporate Technology \\ Siemens Ltd. China \\ Shanghai, China
}

\author{
Michael Anheuser \\ IC LMV LV GP R\&D PD \\ Siemens AG \\ Amberg, Germany
}

\begin{abstract}
The algorithm for detecting the short circuit current in its early stage greatly helps low voltage protection devices to make improvements in current limitation. Based on the analysis the working principle of the early short circuit detection technology, the new method of polyhedron criterion has been proposed. The short circuit current is predicted based on the relationship among the instantaneous values of current, current $1^{\text {st }}$ derivative and current's 2 nd derivative with respect to time as a combined criterion. And the simulation and experiment results are presented and the results validate its good performance.
\end{abstract}

Key words: current limitation, early short circuit detection; lowvoltage networks;

\section{INTRODUCTION}

Low voltage protection device, e.g., circuit breaker, are designed to handle with the problems of the short circuit. Electrical systems (e.g. conductor lines, cables, bus bar systems) and loads (e.g. machines) are stressed electrodynamically and thermally by short-circuit currents. The amount of stress is affected primarily by the amplitude of the short-circuit current and the time from short-circuit occurrence until switch off. In some cases, the short circuit current with the range of 10 to $150 \mathrm{kA}$ (at $440 \mathrm{~V}$ ) can be expected in lowvoltage networks. Thus, it is vitally important to isolate the fault as soon as possible to minimize downtime and damage. Naturally, the concept of early short circuit detection which detects the short circuit current in its early stage can greatly facilitate the protection action of the low voltage protection device to start the current limiting as soon as possible. Therefore faster and reliable detection algorithms are needed to realize fault detection.

\section{WORKING PRINCIPLE}

\section{A. Stat-of-art of early short circuit detection}

To realize the early short circuit detection, locus curves criteria [1], regression method [2], modeling method [3] wavelet method [4] have been proposed by a lot of researchers. As pointed out in the overview of early short-circuit detection algorithms [5], the method of locus curve fundamental on early short circuit current detection shows high performance considering reliability, detection time and complexity.

\section{B. Locus circuve method}

There are a lot of researches regarding the application of locus curve method on early short circuit current detection. Locus curve method is based on the analysis of the instantaneous current value and its derivative value at the same time point. The basic working principle of locus curve method is based on an ohmic-inductive equivalent circuit as shown in Fig. 1, where $\mathrm{V}_{\mathrm{m}}$ is maximum voltage of the power source, $\mathrm{w}$ is the frequency of the power source in $\operatorname{rad}, \varphi$ is the switching-on angle, $\cos \theta$ is the power factor which is determined by the inductance $\mathrm{L}$ and resistance $\mathrm{R}$ in the model. The formula (1) (2) below can be got according to the model.

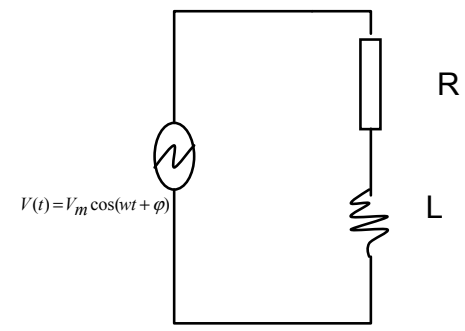

Fig.1 Equivalent circuit

$$
\begin{aligned}
& V_{m} \cos (w t+\varphi)=R i+L i^{\prime} \\
& \tan \theta=\frac{R}{w L}, \cos \theta=\frac{R}{\sqrt{R^{2}+(w L)^{2}}}, I_{p}=\frac{V_{m}}{\sqrt{R^{2}+(w L)^{2}}}
\end{aligned}
$$

where $I_{p}$ is called as the prospective current value.

Thus, the formula can be written as formula (4) with the formula (3) where $I_{r}$ is called as the current threshold value,

$$
\begin{aligned}
& I=\frac{i}{I_{r}} ; I^{\prime}=\frac{d i / d t}{w I_{r}} ; I^{\prime \prime}=\frac{d^{2} i / d t^{2}}{w^{2} I_{r}} \\
& \left(I+\tan \theta \cdot I^{\prime}\right)=\frac{\sqrt{2}}{\cos \theta} \cdot \frac{I_{p}}{I_{r}} \cdot \cos (w t+\varphi)
\end{aligned}
$$

With the consideration of all possible power factor, switching-on angle when $I_{p}=I_{r}$, a locus curve as shown in Fig.2 can be got. Thus, any point of (I, I') which is out of the envelope definitely means that $I_{p}$ is bigger $I_{r}$. By this way, the relationship whether the $I_{p}$ is bigger than $I_{r}$ can be determined by the measured $i$ and its derivative value of i'.

Identify applicable sponsor/s here. (sponsors) 


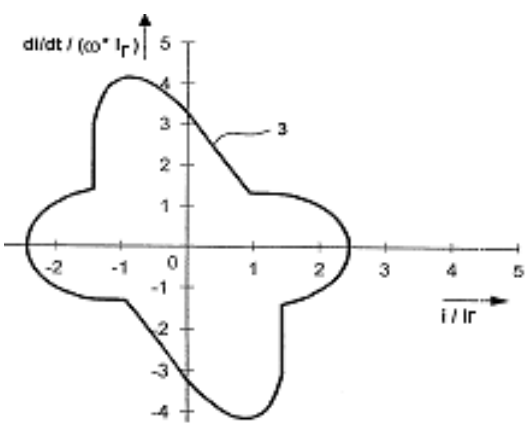

Fig.2 Locus curve method

As pointed out in [5][6], with defined formula (5) of taking advantage of $2^{\text {nd }}$ derivative information, a cubical criteria can be got,

$$
I^{\prime \prime}=\frac{d^{2} i / d t^{2}}{w^{2} I_{r}}
$$

And by solving the formula (1), the maximum values (c, b, a) of the I, I' and I' can be determined with possible conditions. Then a cubical as shown in Fig. 3 is figured out. Any points of (I, I', I') which is out of the cubiod (satisfying the formula (6)) obviously means a short circuit current with $\mathrm{I} p>\mathrm{I}_{\mathrm{r}}$. With this method, the fault detection time performance is improved.

$$
\left|I=\frac{i}{I_{r}}\right|>c\left\|\left|I^{\prime}=\frac{d i / d t}{w I_{r}}\right|>b\right\|\left|I^{\prime \prime}=\frac{d^{2} i / d t^{2}}{w^{2} I_{r}}\right|>a
$$

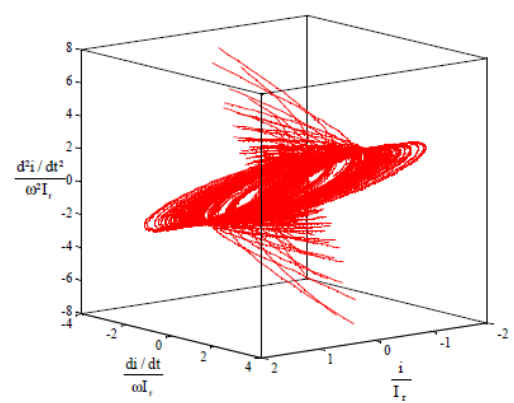

Fig.3 Cubical criterion

However, it can be found that some points inside of the cubiod maybe the short circuit current with $\mathrm{I}_{\mathrm{p}}>\mathrm{I}_{\mathrm{r}}$. In order to overcome this kind of drawbacks, a new method of taking full advantage of the constrain relationship among I, I' and I' are proposed in this paper. The following formula (7) can be got based on formula (4),

$\left(I^{\prime}+\tan \theta \cdot I^{\prime \prime}\right)=-\frac{\sqrt{2}}{\cos \theta} \cdot \frac{I_{p}}{I_{r}} \cdot \sin (w t+\varphi)$

With formula (4) and (7), formula (8) can be got,

$\left(I+(1+\tan \theta) \cdot I^{\prime}+\tan \theta \cdot I^{\prime \prime}\right)=\frac{\sqrt{2}}{\cos \theta} \cdot \frac{I_{p}}{I_{r}} \cdot[\cos (w t+\varphi)-\sin (w t+\varphi)]$

It is well known in formula (9),

$|\cos (w t+\varphi)| \leq 1, \quad|\sin (w t+\varphi)| \leq 1, \quad|\cos (w t+\varphi)-\sin (w t+\varphi)| \leq \sqrt{2}$

Then, when any formula of (10), (11) or (12) is satisfied, the $\mathrm{I}_{\mathrm{p}}>\mathrm{I}_{\mathrm{r}}$ can be assured.
$\left|I^{\prime}+\tan \left(\theta_{1}\right) I^{\prime \prime}\right|>\frac{\sqrt{2}}{\cos \left(\theta_{1}\right)} \& \&\left|I^{\prime}+\tan \left(\theta_{2}\right) I^{\prime \prime}\right|>\frac{\sqrt{2}}{\cos \left(\theta_{2}\right)}$

$\left|I+\tan \left(\theta_{1}\right) I^{\prime}\right|>\frac{\sqrt{2}}{\cos \left(\theta_{1}\right)} \& \&\left|I+\tan \left(\theta_{2}\right) I^{\prime}\right|>\frac{\sqrt{2}}{\cos \left(\theta_{2}\right)}$

$\left|I+\left(1+\tan \left(\theta_{1}\right)\right) I^{\prime}+\tan \left(\theta_{1}\right) I^{\prime \prime}\right|>\frac{2}{\cos \left(\theta_{1}\right)} \& \&\left|I+\left(1+\tan \left(\theta_{2}\right)\right) I^{\prime}+\tan \left(\theta_{2}\right) I^{\prime \prime}\right|>\frac{2}{\cos \left(\theta_{2}\right)}$

where the $\theta_{1}$ and $\theta_{2}$ are the phase shift between the current and the voltage when using possible maximum, minimum power factors respectively.

With above analysis, a polyhedron can be figured out by applying the constrain relationship as shown in Fig. 4.

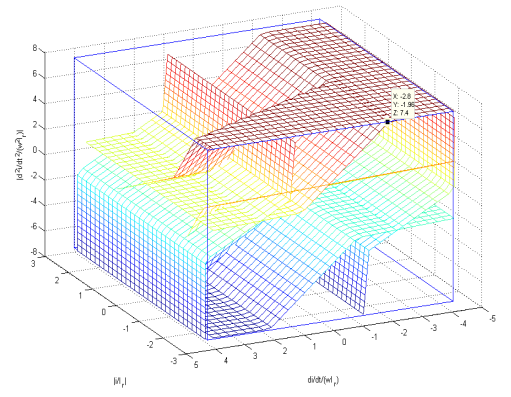

Fig.4 Polyhedron criterion

\section{Realization of Polyhedron criterion}

It is necessary to point out that the calculation of I' is often sensitive to noise as also mentioned in the cubical criterion. Then the strategy of assigning different coefficients of the judgment involving I, I' and I' is applied. The detail flow chart of the polyhedron criterion is shown in Fig. 5.

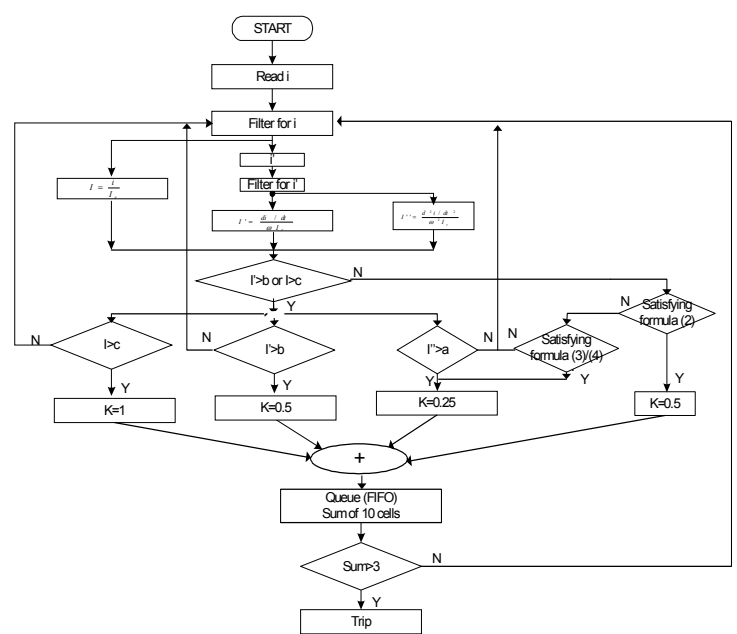

Fig.5 Flow chart of polyhedron criterion

\section{SIMULATION AND TEST}

In order to validate the proposed method, both the simulation and experiment test have been conducted. Considering the practical application, the $I_{\mathrm{r}}$ is always set as $10 \mathrm{I}_{\mathrm{n}}$. The practical criterion for evaluating the early short circuit detection algorithm is that the algorithm should forecast all the short circuit current with $\mathrm{I}_{\mathrm{p}}>12 \mathrm{I}_{\mathrm{n}}$ and should not forecast all the short circuit current with $\mathrm{I}_{\mathrm{p}}<8 \mathrm{I}_{\mathrm{n}}$ while considering some 
allowable tolerance. As shown in the table 1 and table 2, the result which is satisfying the evaluation criterion will be marked in the green background, and the result which is not satisfying the criterion will be marked in the red background.

\section{A. Simulation with simulated short circuit current}

The following generated 30 short circuit currents $\left(\mathrm{I}_{\mathrm{n}}=250 \mathrm{~A}\right.$, time duration is $\left.10 \mathrm{~ms}\right)$ in the table 1 have been applied as the input current for the corresponding Matlab program of the polyhedron criterion, where the switching on angle is from $0^{\circ}$ to $180^{\circ}$ and the $\mathrm{I}_{\mathrm{p}}$ of $5 \mathrm{I}_{\mathrm{n}}, 10 \mathrm{I}_{\mathrm{n}}, 20 \mathrm{I}_{\mathrm{n}}, 40 \mathrm{I}_{\mathrm{n}}$, and $50 \mathrm{I}_{\mathrm{n}}$. The detection time means the time period between the time of short circuit and the time when the algorithm detects it. And the results via cubical criterion are also simulated as reference.

Table 1 Simulation results

\begin{tabular}{|c|c|c|c|c|c|c|c|c|c|c|c|c|}
\hline $\begin{array}{c}\text { Simulated } \\
\text { SC current } \\
\left(\mathrm{I}_{\mathrm{n}}=250 \mathrm{~A}\right)\end{array}$ & \multicolumn{3}{|c|}{$\begin{array}{c}\text { Cubical criterion method } \\
\left(\mathrm{I}_{\mathrm{r}}=10 \mathrm{I}_{\mathrm{n}}=2500 \mathrm{~A}\right) \\
\text { Detection time }(\mathrm{ms})\end{array}$} & \multicolumn{5}{c|}{$\begin{array}{c}\text { Polyhedron criterion method } \\
\left(\mathrm{I}_{\mathrm{r}}=10 \mathrm{I}_{\mathrm{n}}=2500 \mathrm{~A}\right) \\
\text { Forecast time (ms) }\end{array}$} \\
\hline $\begin{array}{c}\text { Switching- } \\
\text { on } \\
\text { angle }\left({ }^{\circ}\right)\end{array}$ & 0 & 30 & 60 & 90 & 120 & 150 & 0 & 30 & 60 & 90 & 120 & 150 \\
\hline $\begin{array}{c}1.25 \mathrm{kA} \\
\left(5 \mathrm{I}_{\mathrm{n}}\right)\end{array}$ & $\backslash$ & $\backslash$ & $\backslash$ & $\backslash$ & $\backslash$ & $\backslash$ & $\backslash$ & $\backslash$ & $\backslash$ & $\backslash$ & $\backslash$ & $\backslash$ \\
\hline $\begin{array}{c}2.5 \mathrm{kA} \\
\left(10 \mathrm{I}_{\mathrm{n}}\right)\end{array}$ & $\backslash$ & $\backslash$ & $\backslash$ & $\backslash$ & $\backslash$ & $\backslash$ & $\backslash$ & $\backslash$ & $\backslash$ & $\backslash$ & $\backslash$ & $\backslash$ \\
\hline $\begin{array}{c}5 \mathrm{kA} \\
\left(20 \mathrm{I}_{\mathrm{n}}\right)\end{array}$ & $\backslash$ & $\backslash$ & $\backslash$ & $\backslash$ & $\backslash$ & $\backslash$ & 2.7 & 1.35 & 1.1 & 1.0 & 1.3 & 4.4 \\
\hline $\begin{array}{c}10 \mathrm{kA} \\
\left(40 \mathrm{I}_{\mathrm{n}}\right)\end{array}$ & 4.0 & 2.65 & 1.5 & 1.45 & 7.05 & 5.85 & 1.85 & 0.8 & 0.55 & 0.6 & 0.75 & 3.75 \\
\hline $\begin{array}{c}12.5 \mathrm{kA} \\
\left(50 \mathrm{I}_{\mathrm{n}}\right)\end{array}$ & 3.5 & 1.9 & 1.2 & 1.1 & 6.4 & 5.0 & 1.7 & 0.75 & 0.55 & 0.55 & 0.65 & 3.7 \\
\hline
\end{tabular}

It can be found that the better performance can be achieved via polyhedron criterion method.

\section{B. Experiment with practical short circuit current}

With a built demonstrator, the algorithms are also tested with the 9 practical short circuit currents $\left(I_{n}=400 A\right)$. And the table 2 shows the results.

Table 2 Experiment results

\begin{tabular}{|c|c|c|}
\hline $\begin{array}{c}\text { Measurement } \\
\text { SC current } \\
\left(\mathrm{I}_{\mathrm{n}}=400 \mathrm{~A}\right)\end{array}$ & $\begin{array}{c}\text { Cubical criterion method } \\
\left(\mathrm{I}_{\mathrm{r}}=10 \mathrm{I}_{\mathrm{n}}=4000 \mathrm{~A}\right) \\
\text { Detection time }(\mathrm{ms})\end{array}$ & $\begin{array}{c}\text { Polyhedron criterion } \\
\text { method } \\
\left(\mathrm{I}_{\mathrm{r}}=10 \mathrm{I}_{\mathrm{n}}=4000 \mathrm{~A}\right) \\
\text { Detection time }(\mathrm{ms})\end{array}$ \\
\hline $4,0 \mathrm{kA}\left(10 \mathrm{I}_{\mathrm{n}}\right)$ & $\backslash$ & 1.60 \\
\hline $6,1 \mathrm{kA}\left(\sim 15 \mathrm{I}_{\mathrm{n}}\right)$ & $\backslash$ & 2.32 \\
\hline $8,0 \mathrm{kA}\left(20 \mathrm{I}_{\mathrm{n}}\right)$ & $\backslash$ & 1.96 \\
\hline $10,0 \mathrm{kA}\left(25 \mathrm{I}_{\mathrm{n}}\right)$ & $\backslash$ & 1.67 \\
\hline $12,1 \mathrm{kA}\left(\sim 30 \mathrm{I}_{\mathrm{n}}\right)$ & 3.41 & 1.07 \\
\hline $13,4 \mathrm{kA}\left(33.5 \mathrm{I}_{\mathrm{n}}\right)$ & 3.12 & 1.08 \\
\hline $16,0 \mathrm{kA}\left(40 \mathrm{I}_{\mathrm{n}}\right)$ & 2.68 & 0.88 \\
\hline $18,6 \mathrm{kA}\left(46.5 \mathrm{I}_{\mathrm{n}}\right)$ & 2.36 & 0.80 \\
\hline $19,7 \mathrm{kA}\left(49 \mathrm{I}_{\mathrm{n}}\right)$ & 2.17 & 0.79 \\
\hline
\end{tabular}

It also can be found that the polyhedron criterion method shows better performance that the cubical criterion method.

\section{CONCLUSION}

Early short circuit detection method helps the protection device to take right current limitation action as soon as possible when the short circuit occurs. In this paper, a polyhedron method with high reliability is proposed based on the theoretical analysis of the short circuit model. The simulation results with the simulated short circuit currents and the experiments with the practical short circuit currents validate its realization and good performance.

\section{REFERENCES}

[1] Patent DE 3642136 A1, 1986

[2] M. Öhrström, "Fast fault detection for power distribution systems," Thesis, Royal Institute of Technology, Stockholm, 2003

[3] I. H. Schau, A. Novitskiy, I. Konotop, "Mathematical modeling of voltage dips in electrical LV networks with current-limiting circuit breakers," 39th International Universities Power Engineering Conference (UPEC), Bristol, UK, 2004.

[4] S. Li, "Wavelet Transform Applications in Power Systems," Diss.,University Erlangen-Nuremberg, 2002

[5] T. Muitzel, F. Berger and M. Anheuser, "Methods of Electronic ShortCircuit Detection for Improving Current Limitation in Low-Voltage Systems," 23rd International Conference on Electrical Contacts (ICEC), Sendai, pp. 566-571, 2006.

[6] T. Mützel, F. Berger and M. Anheuser, "New Algorithm for Electronic Short-Circuit Detection," 52nd IEEE Holm Conference on Electrical Contacts, Montreal, Canada, pp. 42-47, 2006. 